OPEN ACCESS

Edited by:

Arianna Maffei,

Stony Brook University, United States

Reviewed by:

Claudia Lodovichi,

Istituto Veneto di Medicina

Molecolare (VIMM), Italy

John M. Bekkers, Australian National University,

Australia

${ }^{*}$ Correspondence:

Michael T. Shipley mshipley@som.umaryland.edu

Received: 25 July 2018 Accepted: 09 October 2018 Published: 26 October 2018

Citation:

Zhou F-W, Puche AC and Shipley MT (2018) Short-Term Plasticity at Olfactory Cortex to Granule Cell Synapses Requires Cav2.1 Activation. Front. Cell. Neurosci. 12:387. doi: 10.3389/fncel.2018.00387

\section{Short-Term Plasticity at Olfactory Cortex to Granule Cell Synapses Requires Cav2.1 Activation}

\author{
Fu-Wen Zhou, Adam C. Puche and Michael T. Shipley*
}

Department of Anatomy and Neurobiology, Program in Neurosciences, University of Maryland School of Medicine, Baltimore, MD, United States

Output projections of the olfactory bulb (OB) to the olfactory cortex (OCX) and reciprocal feedback projections from OCX provide rapid regulation of OB circuit dynamics and odor processing. Short-term synaptic plasticity (STP), a feature of many synaptic connections in the brain, can modulate the strength of feedback based on preceding network activity. We used light-gated cation channel channelrhodopsin-2 (ChR2) to investigate plasticity of excitatory synaptic currents (EPSCs) evoked at the OCX to granule cell (GC) synapse in the OB. Selective activation of OCX glutamatergic axons/terminals in OB generates strong, frequency-dependent STP in GCs. This plasticity was critically dependent on activation of Cav2.1 channels. As acetylcholine (ACh) modulates Cav2.1 channels in other brain regions and as cholinergic projections from the basal forebrain heavily target the GC layer (GCL) in OB, we investigated whether ACh modulates STP at the $\mathrm{OCX} \rightarrow \mathrm{GC}$ synapse. ACh decreases OCX $\rightarrow$ GC evoked EPSCs, it had no effect on STP. Thus, ACh impact on cortical feedback is independent of Cav2.1-mediated STP. Modulation of OCX feedback to the bulb by modulatory transmitters, such as ACh, or by frequency-dependent STP could regulate the precise balance of excitation and inhibition of GCs. As GCs are a major inhibitory source for OB output neurons, plasticity at the cortical feedback synapse can differentially impact $\mathrm{OB}$ output to higher-order networks in situations where ACh inputs are activated or by active sniff sampling of odors.

Keywords: short-term synaptic plasticity, Cav2.1 channels, feedback projections, olfactory cortex, olfactory bulb, light-gated cation channel channelrhodopsin-2

\section{INTRODUCTION}

Sensory processing depends on environmental context and the past experiences of an individual. The neural encoding of these past experiences into "memory" is generally thought to occur via synaptic plasticity. Synaptic plasticity within the olfactory bulb (OB) and olfactory cortex (OCX) is thought to be involved in the sensory processing underlying olfactory memory (Wilson et al., 2004). OB mitral/tufted cells (M/TCs) project to the OCX where they synapse the apical dendrites of principal cells (Carson, 1984; Otazu et al., 2015). Olfactory cortical pyramidal cells, in turn send dense excitatory feedback projections to the main OB (Shipley and Ennis, 1996; Ennis et al., 2015). 
Plasticity changes at any of these synapses could modulate sensory processing based on past experience.

Granule cells (GCs) are the major synaptic targets of centrifugal fibers from OCX (Davis and Macrides, 1981; Luskin and Price, 1983; Carson, 1984; Shipley and Adamek, 1984; Balu et al., 2007; Boyd et al., 2012). GCs also receive feedback glutamatergic synaptic projections from anterior olfactory nucleus/cortex (Markopoulos et al., 2012). GCs regulate the activity of $\mathrm{OB}$ output neurons, M/TCs by way of reciprocal dendrodendritic synapses. M/TCs excite GCs, which in turn, reciprocally inhibit M/TCs (Isaacson and Strowbridge, 1998; Mori et al., 2009). Optical activation of OCX pyramidal cell axons/terminals in $\mathrm{OB}$ evokes excitatory postsynaptic currents (EPSCs) in GCs (Boyd et al., 2012). Electrical stimulation of cortical feedback projections to the $\mathrm{OB}$ can evoke long(Cauthron and Stripling, 2014) and short-term (Balu et al., 2007) plasticity at the OCX $\rightarrow$ GC synapse.

Short term plasticity (STP) is widely believed to play an important role in essential neural functions, including sensory processing (Abbott and Regehr, 2004; Wilson et al., 2004; Li et al., 2018). For most neurons the key determinant of STP is calcium influx through presynaptic $\mathrm{P} / \mathrm{Q}$ voltage-dependent calcium channels ( $\mathrm{Ca}_{V} 2.1$; Mochida et al., 2008; Catterall et al., 2013). Cav2.1 channels show slow and fast modes of gating, voltage dependent open probability, slow inactivation and voltage dependent steady-state inactivation (Luvisetto et al., 2004). Cav2.1 channels are highly expressed throughout the $\mathrm{OB}$ and are especially concentrated in presynaptic terminals (Westenbroek et al., 1995).

$\mathrm{Ca}_{\mathrm{V}} 2.1$ channels can also be targets for modulation by transmitters such as acetylcholine (ACh). Activation of ACh receptors reduces calcium entry into the presynaptic terminal to decrease neurotransmission at basket cell synapses in mouse CA1 hippocampus (Lawrence et al., 2015) and at striatal projection neuron synapses (Perez-Rosello et al., 2005). Cholinergic projections from diagonal band (DB) complex in the basal forebrain (Macrides et al., 1981; Luskin and Price, 1983; Nickell and Shipley, 1988) terminate throughout the OB (Ichikawa and Hirata, 1986; Kasa et al., 1995; Rothermel et al., 2014). Many of these cholinergic axons terminate GC spines. Electrical stimulation of $\mathrm{DB}$ in vivo and $\mathrm{ACh}$ applied in slices regulates GC inhibition of mitral cells (Nickell and Shipley, 1988; Castillo et al., 1999). This could be due to direct cholinergic synapses onto GCs or onto presynaptic terminals of glutamatergic excitatory projections from OCX, or both. ACh could directly modulate $\mathrm{Ca}_{\mathrm{V}} 2.1$ channels at either synaptic site, or act independently of $\mathrm{Ca}_{\mathrm{V}} 2.1$ channels to modulate the OCX $\rightarrow$ GC synapse. The present research addresses these issues.

We used light-gated cation channel channelrhodopsin-2 (ChR2) to investigate plasticity of EPSCs at the OCX $\rightarrow$ GC synapse. We report that selective activation of this synapse generates strong, frequency-dependent STP. The plasticity requires activation of $\mathrm{Ca}_{V} 2.1$ channels on $\mathrm{OCX} \rightarrow \mathrm{GC}$ axon terminals. We further report that, although ACh decreases OCX evoked EPSCs, it has no effect on STP.

\section{MATERIALS AND METHODS}

Male and female transgenic vGLUT2-Cre mice from Jackson Laboratory ( $120 \pm 5$ days old, $n=22$ mice) were used. Animals were maintained with a standard $12 \mathrm{~h}$ light/dark cycle and ad libitum access to food and water. All experimental procedures were performed in accordance with protocols approved by the University of Maryland Institutional Animal Care and Use Committee.

ChR2 was expressed by injection of Cre-inducible adenoassociated virus serotype 9 (AAV2.9) as described previously (Liu et al., 2013). Briefly, the skull was exposed and four small holes $(\sim 0.5 \mathrm{~mm}$ diameter; coordination: Bregma, +1.0; lateral, \pm 2.8 ; vertical, -4.0 and Bregma, +1.5 ; lateral, \pm 2.5 ; vertical, -3.8; Franklin and Paxinos, 2008) were drilled for injections in OCX. The AAV2.9, carrying fusion genes for ChR2 and enhanced yellow (AAV2.9-hSyn-hChR2(H134R)EYFP; Liu et al., 2016), were injected at 8-12 weeks postpartum. Injections were performed of $0.25 \mu \mathrm{l}$ over 5 min per injection site.

To increase the yield for the electrophysiology/pharmacology experiments, virus (total $\sim 1.0 \mu \mathrm{l}$ ) was injected into piriform cortex of both hemispheres. In both hemispheres, infected pyramidal cells appeared to be confined to piriform cortex. However, as we cannot definitively rule out some undetected spread into AON, thus we designate the injection site as "OCX" rather than "piriform cortex."

After at least 3 weeks for ChR2-EYFP fluorescent protein expression, acute $\mathrm{OB}$ slices were cut as previous described (Zhou et al., 2016). Briefly, OB was quickly dissected out and horizontal slices $(350 \mu \mathrm{m})$ were cut with a VT1200S Vibratome in $4^{\circ} \mathrm{C}$ oxygenated $\left(95 \% \mathrm{O}_{2}-5 \% \mathrm{CO}_{2}\right)$ cutting solution containing (in $\mathrm{mM}$ ): 204.5 sucrose, $3 \mathrm{KCl}, 1.25 \mathrm{NaH}_{2} \mathrm{PO}_{4}, 25 \mathrm{NaHCO}_{3}$, 2.6 $\mathrm{MgCl}_{2}, 10 \mathrm{D}$-glucose. The slices were then transferred to a holding chamber containing the oxygenated extracellular solution (in $\mathrm{mM}$ ): $125 \mathrm{NaCl}, 2.5 \mathrm{KCl}, 1.25 \mathrm{NaH}_{2} \mathrm{PO}_{4}$, $25 \mathrm{NaHCO}_{3}, 1.3 \mathrm{CaCl}_{2}, 1.3 \mathrm{MgSO}_{4}, 10 \mathrm{D}$-glucose.

After at least $1 \mathrm{~h}$ incubation at $23^{\circ} \mathrm{C}$, slices were transferred to recording chamber and perfused at $5 \mathrm{ml} / \mathrm{min}$ with extracellular solution. Recordings were made at $30^{\circ} \mathrm{C}$ under visual guidance of a BX50WI (Olympus) fixed-stage upright microscope equipped with near-infrared differential interference contrast optics. Conventional whole cell patch clamp techniques were used as previously described (Zhou et al., 2009). Records were performed from GCs located in the GC layer (GCL). Patch electrodes had resistances of 7-8 $\mathrm{M} \Omega$ when filled with an internal solution containing (in $\mathrm{mM}$ ): $120 \mathrm{CsCH}_{3} \mathrm{SO}_{3}$, 5 EGTA, 10 HEPES, $5.5 \mathrm{MgCl}_{2}, 3 \mathrm{Na}_{2}$-ATP, $0.3 \mathrm{Na}_{3}$-GTP, 10 Na-phosphocreatine and $0.1 \%$ biocytin $(280 \mathrm{mOsm}$ and $\mathrm{pH}$ was adjusted to 7.3 with $\mathrm{CsOH}$ ). MultiClamp 700A amplifiers, pClamp 9.2 software and Digidata 1322A interface (Axon Instruments) were used to acquire and analyze data. Signals were digitized at 5-20 KHz and analyzed offline. D-2-amino5-phosphonopentanoic acid (D-AP5) and 2,3-dihydroxy-6nitro-7-sulfamoyl-benzo[f]quinoxaline-2,3-dione (NBQX) were purchased from Tocris and other chemicals were from Sigma. 
Fibers from glutamatergic neurons in OCX with ChR2 expression were activated by green laser optical stimulation and the evoked EPSCs recorded at holding potential of $-60 \mathrm{mV}$. Laser light was generated by a $100 \mathrm{~mW}, 473 \mathrm{~nm}$, diode-pumped, solid-state laser MBL-III-473 (Optoengine) and gated with a high speed laser shutter LST200 (NMLaser Products). Laser beam from fiber tip was calibrated with a PM20A power meter (ThorLabs). Laser beam was delivered from a multimode optical fiber with opening diameter of $25 \mu \mathrm{m}\left(0.1 \mathrm{NA}, \sim 7^{\circ}\right.$ beam divergence). The optical stimulation pulses $(2 \mathrm{~ms})$ were triggered by TTL electrical pulses generated by a PG4000A digital stimulator (Cygnus Technology). The laser light output was $0-8.55 \mathrm{~mW}$ (or $0-17.4 \times 10^{-3} \mathrm{~mW} / \mu \mathrm{m}^{-2}$ with the tip of a $25-\mu \mathrm{m}$ core diameter fiber, $1 \mathrm{~mW}$ corresponding to $2 \times 10^{-3}$ $\mathrm{mW} / \mu \mathrm{m}^{-2}$ ). The interstimulus intervals (or stimulation frequencies) varied from $50 \mathrm{~ms}$ to $500 \mathrm{~ms}$ (or 20-2 Hz) controlled by a MultiClamp 700A commander (Molecular Devices, San Jose, CA, USA).

After electrophysiological recordings, staining was performed as described previously (Zhou and Roper, 2011). Briefly, brain slices with bicytin-filled GCs were fixed in 4\% paraformaldehyde (PFA) in $0.1 \mathrm{M}$ phosphate buffer (PBS) at $4^{\circ} \mathrm{C}$ overnight or longer. Slices were incubated with $4 \mu \mathrm{g} / \mathrm{mL}$ Alexa Fluor 546 streptavidin for $2 \mathrm{~h}$ at room temperature. After washing in PBS, slices were incubated with DAPI $(300 \mathrm{nM})$ for $1 \mathrm{~h}$. Slices were then mounted on glass slides, coverslipped with a DABCO based antifade media and imaged. Digital microscopy images were captured using a FluoView500 confocal microscope (Olympus).

Data were analyzed with Clampfit 9.2 (Molecular Devices, San Jose, CA, USA). Peak amplitude was measured as the difference between the baseline current level and the peak of the EPSC. Rise time was defined as the time taken for the current to rise from $10 \%$ to $90 \%$ of EPSC peak amplitude; decay time was the time to decrease from $90 \%$ to $10 \%$ EPSC peak amplitude. The paired pulse ratio (PPR) was calculated as the ratio of the peak amplitude of the test (second) EPSC to that of the control (first) EPSC. Statistical analysis and both graphs and plotting were completed with Origin 2018 (Origin Lab). All values were expressed as mean \pm SEM. Paired $t$-tests and ANOVA were used to compare data.

\section{RESULTS}

\section{Frequency Dependent Short-Term Plasticity}

To investigate glutamatergic synapses from OCX to GCs in the $\mathrm{OB}$, we expressed $\mathrm{ChR} 2$ by injecting the adenoassociated virus AAV2.9-hSyn-hChR2(H134R)-EYFP into OCX of vGLUT2-Cre mice. This drives Cre-dependent co-expression of the lightactivated channel ChR2 and enhanced yellow fluorescent protein (YFP). YFP-labeled glutamatergic cells were observed in layers II-III of OCX as expected for expression of vGLUT2 (Figure 1A). Labeled axons/terminals were predominantly in the GCL and inner part of external plexiform layer (EPL), with only sparse fibers present in the glomerular layer (GL; Figures 1A,B) consistent with previous reports of olfactory cortical projections
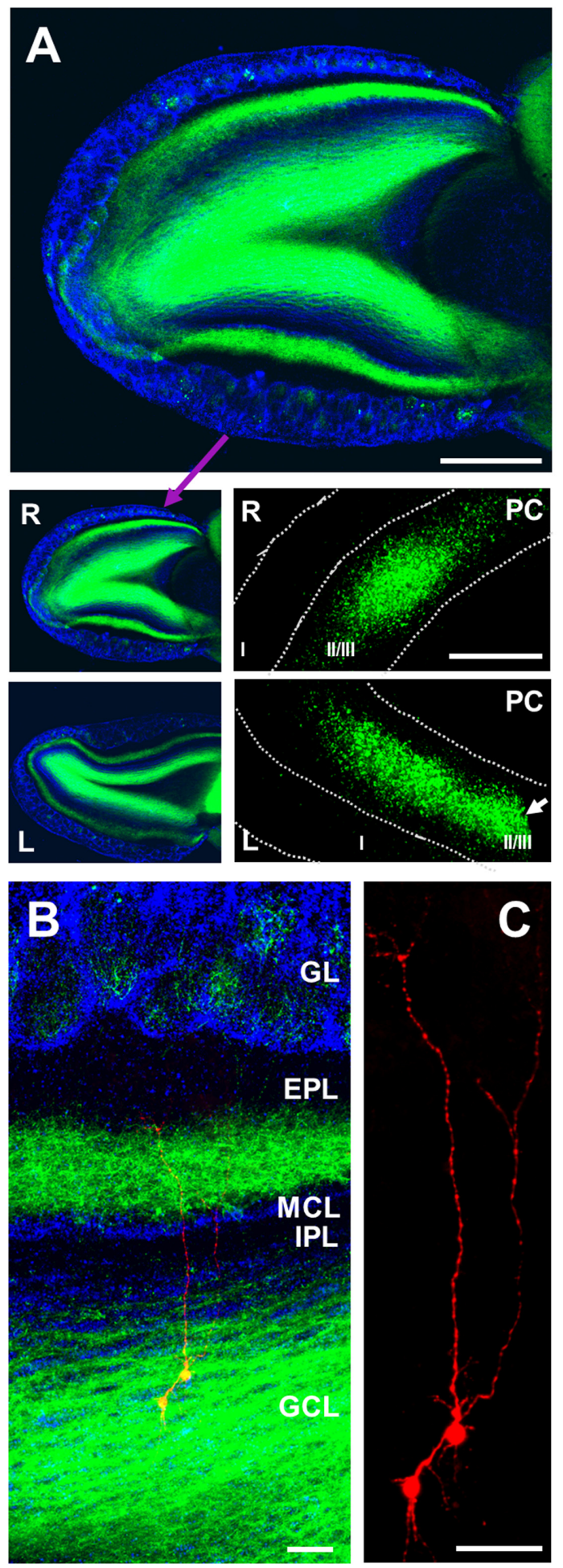

FIGURE 1 | Anterograde labeling of cortico-bulbar glutamatergic axons. (A) Staining of channelrhodopsin-2 (ChR2; green) and DAPI (b/ue) showing distribution of labeled axons (green) in different layers of right (R) olfactory bulb $(\mathrm{OB})$ with the densest labeling in granule cell layer (GCL), and second densest labeling in inner part of external plexiform layer (EPL). Limited fiber labeling is present in glomerular layer (GL), superficial EPL, internal plexiform

(Continued) 


\section{FIGURE 1 | Continued}

layer (IPL) and mitral cell layer (MCL). Left (L) OB is also shown (low panel) a similar distribution of labeled axons from olfactory cortex (OCX). Note that left bulb was from cutting level of around 1,000-1,350 $\mu \mathrm{m}$, and right bulb from around 300-650 $\mu \mathrm{m}$ to dorsal surface of OB. The right and left OCX with infected pyramidal cells are also shown (low panels), but the left one was cut to reduce slice size during the cutting process (white arrow). Scale bar: $400 \mu \mathrm{m}$ in upper panel, and 1,000 $\mu \mathrm{m}$ in lower panel. (B) Triple staining of DAPI (b/ue), ChR2 (green) and biocytin (red) filling two patch clamped GCs with their somata located in the GCL and apical dendritic trunks projecting to ramify in the EPL. (C) Higher magnification showing the biocytin filled cells exhibit the classic dendritic arbor of GCs. Scale bar in (B,C): $50 \mu \mathrm{m}$.

(Luskin and Price, 1983; Shipley and Adamek, 1984; Diodato et al., 2016; Mazo et al., 2016). Interestingly, labeled fibers were present in the inner parts of the EPL in the majority of our cases, this layer has been considered a sparse target for OCX innervation. OCX pyramidal cells do project with differential density to different layers of the main $\mathrm{OB}$, and the viral injection targets/vGlut expressing cells may have different distribution patterns than those of earlier tract tracing studies. Moreover, the number of OCX cells expressing ChR2 may have been greater than previous studies. The EPL labeling could also be due to undetected spread into AON (see "Materials and Methods" section).

We recorded cells located within the GCL, filling all cells with biocytin followed by post hoc immunohistochemical staining to verify that they matched classic GC morphology (Figure 1C). GCs were held at $-60 \mathrm{mV}$ and ChR2-expressing axons and terminals from OCX optically stimulated. In all cells tested light activation of ChR2 fibers evoked a robust EPSC which was completely blocked by AMPA/kainate receptor antagonist NBQX $(n=5)$ but not affected by NMDA receptor antagonist D-AP5 ( $n=5$; Figure 2A). Light intensity was systematically varied to generate an EPSC amplitude-stimulation intensity relationship with EPSC peak amplitude increasing linearly with increments of stimulation intensity from $0 \mathrm{~mW}$ to $3.0 \mathrm{~mW}$ (Figures 2B,C, $n=5$ ). In order to observe either increased or decreased EPSC amplitude in the paired-pulse experiments below, an intermediate stimulation intensity of $\sim 1.7 \mathrm{~mW}$ was used.

Paired pulse optical activation was applied at $2-20 \mathrm{~Hz}$ (interstimulus intervals 50-500 ms) and PPRs were calculated. At the highest frequency tested $(20 \mathrm{~Hz} / 50 \mathrm{~ms})$, there was a significant short-term depression (ratio $0.733 \pm 0.051$ ). As frequency decreased the paired pulse depression (PPD) converted to paired pulse facilitation (PPF). At $13.3 \mathrm{~Hz}$ the PPR was close to 1 (ratio $1.095 \pm 0.053$ ). However, as frequency decreased into sniff/respiratory ranges facilitation was apparent at $10 \mathrm{~Hz}$ (ratio $1.321 \pm 0.061$ ), peaking at $8 \mathrm{~Hz}$ (ratio $1.373 \pm 0.072$ ) before declining back to neutral (ratio $1.062 \pm 0.061$ ) at $2 \mathrm{~Hz}$ (Figures 3A,D, $n=6$ for all tested frequencies). This suggests that at paired-pulse frequencies corresponding to sniffing rates $(4-10 \mathrm{~Hz})$ there is pronounced short term facilitation of OCX glutamatergic synaptic inputs to GCs, while at resting respiration rates around $2 \mathrm{~Hz}$ there is neither depression or facilitation.
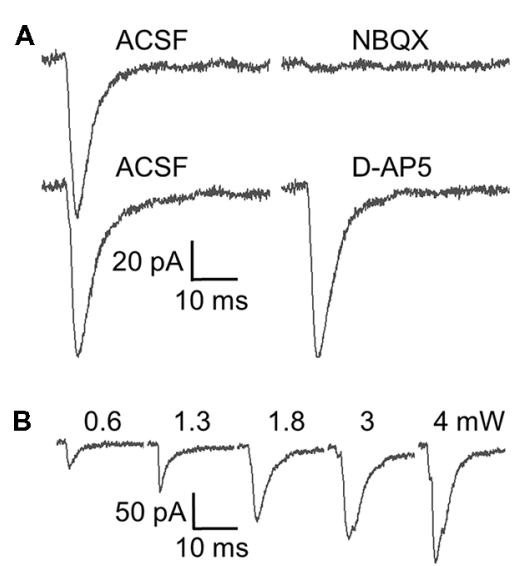

C

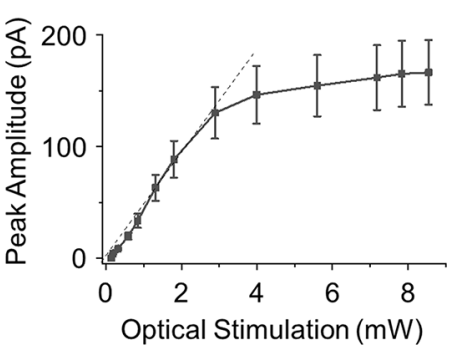

FIGURE 2 | Optical stimulation of ChR2 expressing OCX axons elicits robust excitatory synaptic currents (EPSCs) in GCs. (A) Optically evoked GC EPSCs are blocked by the AMPA/kainate receptor antagonist

2,3-dihydroxy-6-nitro-7-sulfamoyl-benzo[f]quinoxaline-2,3-dione (NBQX;

$10 \mu \mathrm{M}, n=5)$. No change in EPSC was observe with block of NMDA receptors with the antagonist D-2-amino-5-phosphonopentanoic acid (D-AP5; $50 \mu \mathrm{M}, n=5)$. The rise time, decay time and peak amplitude was $1.77 \pm 0.27 \mathrm{~ms}, 10.33 \pm 1.34 \mathrm{~ms}$ and $104.31 \pm 14.33 \mathrm{pA}$ in ACSF and $1.71 \pm 0.32 \mathrm{~ms}, 10.02 \pm 1.29 \mathrm{~ms}$ and $109.8 \pm 13.76 \mathrm{pA}$ in D-AP5, respectively, and they were no difference. (B) Representative EPSCs elicited by varying optical power from $0 \mathrm{~mW}$ to $4 \mathrm{~mW}$. (C) Curve fitting of the power-response profile shows a linear response from $0 \mathrm{~mW}$ to $3 \mathrm{~mW}$ with response amplitude plateauing out to $8 \mathrm{~mW}(n=5)$.

\section{Short-Term Plasticity Requires Cav2.1 Channel Activation}

Calcium channels are major contributors to short-term synaptic plasticity (STP) of neurotransmission (Catterall et al., 2013) and Cav2.1 type channels are highly expressed in presynaptic terminals in the OB (Westenbroek et al., 1995). To investigate the role of $\mathrm{Ca}_{V} 2.1$ channels in STP at the OCX $\rightarrow$ GC synapse, we examined the effect of the selective, irreversible $\mathrm{Ca}_{V} 2.1$ channel blocker, $\omega$-agatoxin IVA (Mintz et al., 1992) on PPD/facilitation. Previous slice studies used concentrations ranging from $50 \mathrm{nM}$ to $500 \mathrm{nM}$ in OB (Wang et al., 1996) and other brain regions (Mochida et al., 2008; Nimmrich and Gross, 2012). To determine an effective dose range for the OCX $\rightarrow$ GC synapse we generated a dose-response curve from $1 \mathrm{nM}$ to $200 \mathrm{nM}$ for reduction of EPSC peak amplitude $(n=4-5$; Figure $3 B$ ). At a low dose of $1 \mathrm{nM}$ there was an amplitude reduction of $6.3 \pm 3.8 \%$ compared to control while at the high dose of $200 \mathrm{nM}$ EPSC amplitude was reduced by $85.5 \pm 5.4 \%$. The half-amplitude reduction (IC50) was at $11.8 \pm 1.4 \mathrm{nM}$. The effect of $\omega$-agatoxin IVA was 


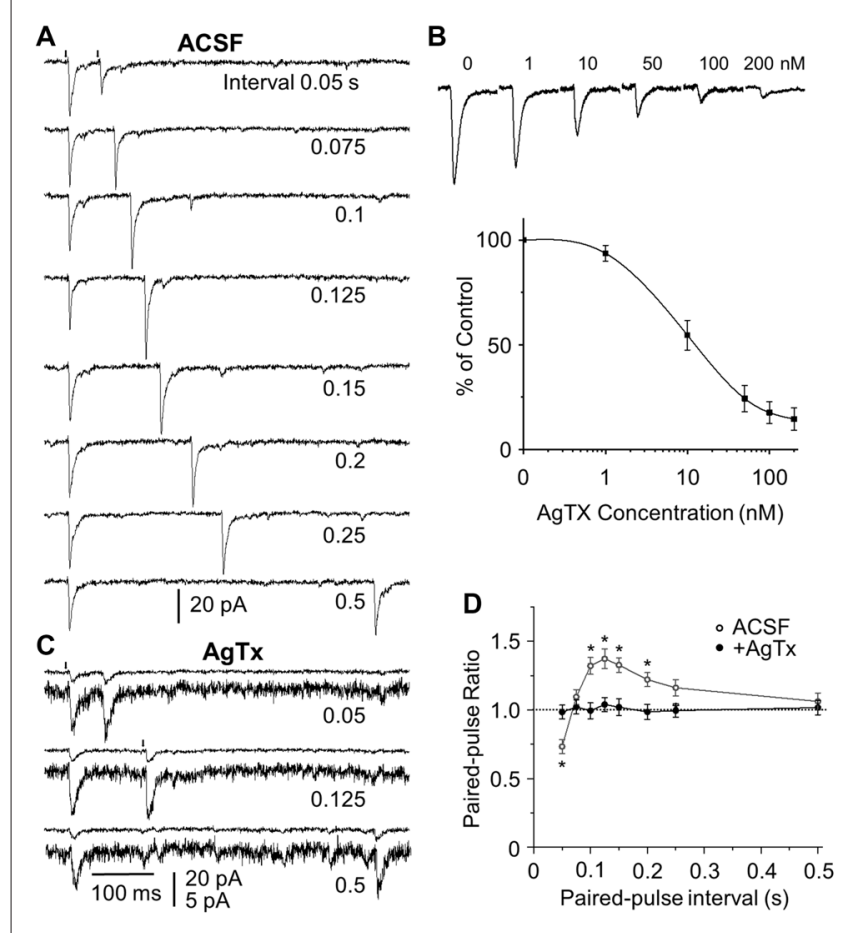

FIGURE 3 | Frequency dependent short-term plasticity (STP) at the OCX to GC synapse requires Cav2.1 calcium channels. (A) Representative traces of paired pulse optical stimulation (arrows) at interstimulus intervals of $0.05-0.5 \mathrm{~s}$ (corresponding to stimulation frequencies of $2-20 \mathrm{~Hz}$ ) in ASCF. (B) Dose response curve for $\omega$-agatoxin IVA. EPSC traces in the presence of bath applied $\omega$-agatoxin IVA (AgTx), the Cav2.1 irreversible antagonist from $0 \mathrm{nM}$ to $200 \mathrm{nM}$ (upper panel) and population data of EPSC peak amplitude expressed as the percentage of the control $(0 \mathrm{nM})$ amplitude $(n=4-5)$. (C) Bath application of AgTx (100 nM) reduces EPSC amplitude and eliminates short term synaptic plasticity. To show the difference of the control and test EPSC peak amplitude, three sets of double traces are shown: one upper trace has the same scale as (A) and the other one has expanded scale. (D) Population data $(n=6)$ showing the paired pulse ratio (PPR) in ASCF (open circle) and in the presence of $\omega$-agatoxin IVA (closed circles). The control EPSCs had the similar peak amplitudes from different stimulation intervals. However, the test EPSC peak amplitude might be different from that of the controls, as shown PPRs different from 1. The rise and the decay time were the same. For example, at the interstimulus interval of $0.125 \mathrm{~s} / 8 \mathrm{~Hz}$, control and test rise time, decay time and peak amplitude was $1.75 \pm 0.30$ and $1.71 \pm 0.27 \mathrm{~ms}$, $9.82 \pm 1.57$ and $9.73 \pm 1.49 \mathrm{~ms}, 101.42 \pm 15.31$ and $139.71 \pm 17.9 \mathrm{pA}$ in ACSF, and $1.84 \pm 0.41$ and $1.87 \pm 0.39 \mathrm{~ms}, 9.04 \pm 1.72$ and

$9.11 \pm 1.69 \mathrm{~ms}, 18.34 \pm 2.58$ and $18.95 \pm 2.67 \mathrm{pA}$ in AgTX. Significant difference at ${ }^{*} P<0.01$.

unchanged upon $30 \mathrm{~min}$ washout consistent with irreversible binding.

To test $\mathrm{Ca}_{V} 2.1$ channel involvement in $\mathrm{OCX} \rightarrow \mathrm{GC}$ STP, $50 \mathrm{nM}$ or $100 \mathrm{nM}$ of $\omega$-agatoxin IVA were selected from our dose- response curve to be "strong" but not completely blocking $\mathrm{Ca}_{V} 2.1$ channels. This compared favorably with doses used to investigate STP in other brain regions (Mochida et al., 2008; Chamberland et al., 2017). Both $50 \mathrm{nM}$ and $100 \mathrm{nM}$ completely blocked STP resulting in a PPR $\sim 1.0$ across all frequencies tested from $2 \mathrm{~Hz}$ to $20 \mathrm{~Hz}(n=6$; Figures 3C,D, 5B,D). Thus, blocking $\mathrm{Ca}_{V} 2.1$ channels completely abolishes STP at the OCX $\rightarrow$ GC synapse indicating that the Cav2.1 channels are necessary for frequency-dependent STP at the glutamatergic $\mathrm{OCX} \rightarrow \mathrm{GC}$ synapse.

\section{Acetylcholine Reduces EPSC Amplitude, but Does Not Change Short Term Plasticity}

Cholinergic axons from the basal forebrain innervate all the layers of the OB. Recently they have been reported to form synaptic contacts with the dendrites of GCs (Liberia et al., 2015). ACh has also been implicated in modulation of $\mathrm{Ca}_{V} 2.1$ calcium channels in other brain regions (Perez-Rosello et al., 2005; Lawrence et al., 2015). To investigate a potential role of ACh at the $\mathrm{OCX} \rightarrow \mathrm{GC}$ synapse we first compared the dose-response curves to optically evoked OCX $\rightarrow$ GC EPSCs before and after bath applied ACh. Increasing doses of ACh from $5 \mu \mathrm{M}$ to $100 \mu \mathrm{M}$ reduced the amplitude of optically evoked EPSCs with $\mathrm{IC}_{50}$ at approximate $28.9 \pm 4.3 \mu \mathrm{M}$ of $\mathrm{ACh}(n=4-6$; Figure 4). We tested $125 \mu \mathrm{M}$ ACh for three cells showing a similar EPSC peak amplitude (not shown) to $100 \mu \mathrm{M}$ ACh and treated $100 \mu \mathrm{M}$ as a presumed saturation concentration for EPSC inhibition.

As $\mathrm{ACh}$ and antagonism of $\mathrm{Ca}_{\mathrm{V}} 2.1$ both reduce glutamatergic synaptic transmission from the OCX, we hypothesized that ACh may act on $\mathrm{Ca}_{\mathrm{V}} 2.1$ channels in OCX synaptic terminals. To explore this possibility, we examined whether ACh attenuates STP at the OCX $\rightarrow$ GC synapse. Bath application of $50 \mu \mathrm{M}$ ACh decreased the peak amplitude of both the control and test EPSC in a paired pulse experiment and washout of $\mathrm{ACh}$ restored EPSC amplitude ( $n=6$; Figure 5A). However, ACh decreased the amplitude of control and test EPSC in a proportional relationship, such that STP was unaltered (Figures 5A,C,D). As in control experiments, high frequency $(20 \mathrm{~Hz})$ resulted in a PPD, while slower frequencies (4 and $8 \mathrm{~Hz}$ ) elicited facilitation (Figures 5A,C). Even ACh at higher concentration (100 $\mu \mathrm{M} ; n=3$ cells) strongly suppressed EPSC amplitude, but did not change PPR (not shown). This suggests that ACh does not act on Cav2.1 channels. To further test this, we
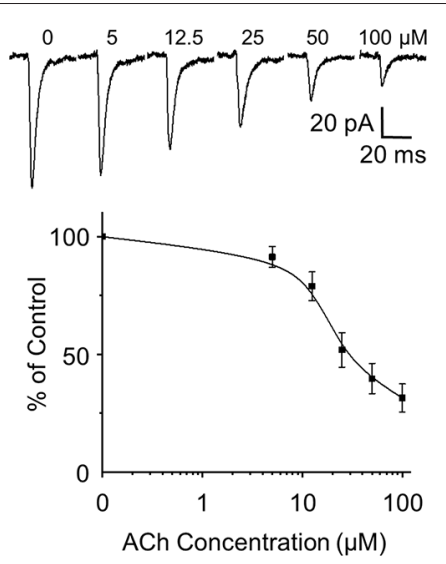

FIGURE 4 | Dose response curve for acetylcholine (ACh). EPSC traces in the presence of bath applied ACh from $0 \mu \mathrm{M}$ to $100 \mu \mathrm{M}$ (upper panel) and population data of EPSC peak amplitude expressed as the percentage of the control $(0 \mu \mathrm{M})$ amplitude $(n=4-6)$. 


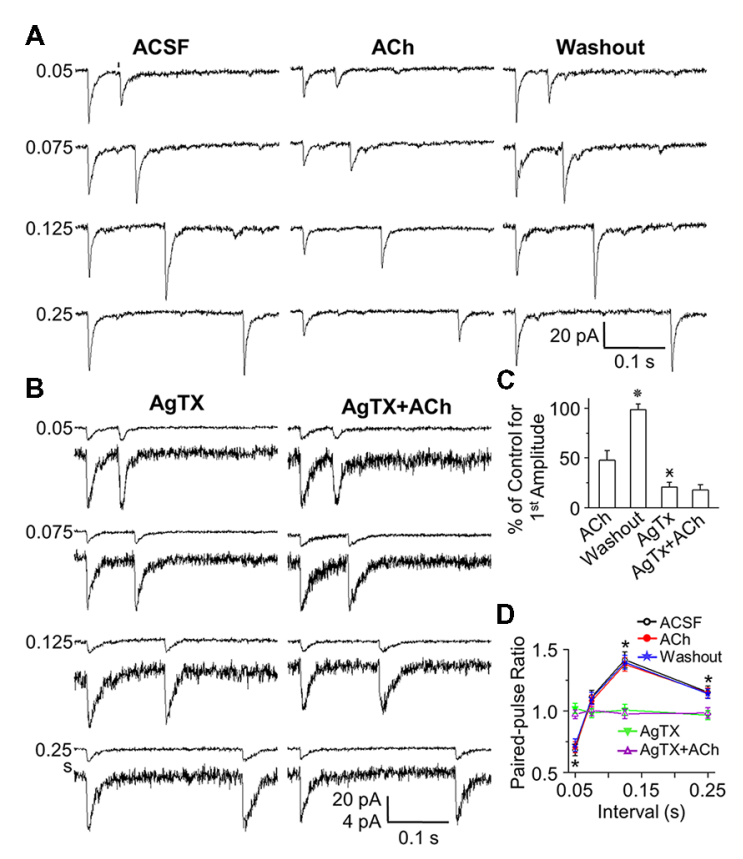

FIGURE 5 | ACh reduces optical stimulation-evoked EPSC peak amplitude, but does not change STP. (A) Representative traces of paired pulse optical stimulation (arrows) evoked EPSCs at interstimulus intervals of 0.05, 0.075, 0.125 and $0.25 \mathrm{~s}$ (corresponding to stimulation frequencies of 20,13.3, 8 and $4 \mathrm{~Hz}$ in ACSF (control), during bath application of ACh $(50 \mu \mathrm{M})$, and after washout. (B) Representative traces of paired pulse optical stimulation evoked EPSCs in the presence of AgTX (50 nM) and AgTx (50 nM) plus ACh (50 $\mu \mathrm{M})$. (C) Population data showing EPSC amplitude as a percentage of ACSF amplitude. (D) Population data $(n=6)$ showing PPR under control (open circle), in the presence of ACh (red circle), following ACh washout (star) and in the presence of AgTX (triangle) and AgTX/ACh (open triangle). The control EPSCs were similar, but they might be different from that of the test EPSC peak amplitude. The rise and the decay time were the same. For instance, at interval of $0.125 \mathrm{~s} / 8 \mathrm{~Hz}$, control and test rise time, decay time and peak amplitude was $1.72 \pm 0.27$ and $1.67 \pm 0.33 \mathrm{~ms}, 10.22 \pm 1.47$ and $10.07 \pm 1.58 \mathrm{~ms}, 96.84 \pm 13.95$ and $136.78 \pm 16.23 \mathrm{pA}$ in ACSF, and $1.61 \pm 0.38$ and $1.65 \pm 0.43 \mathrm{~ms}, 9.36 \pm 1.66$ and $9.43 \pm 1.72 \mathrm{~ms}$, $45.42 \pm 5.34$ and $63.77 \pm 5.94 \mathrm{pA}$ in ACh. Statistical significance * $P<0.01$ vs. ACh; ${ }^{*} P<0.01$ vs. Washout; ${ }^{*} P<0.01$ vs. AgTx.

applied both $\omega$-agatoxin IVA $(50 \mathrm{nM})$ and ACh $(50 \mu \mathrm{M})$. Blocking Cav2.1 reduced EPSC amplitude and abolished STP as above. However, addition of ACh did not significantly increase the EPSC attenuation observed with $\mathrm{Ca}_{V} 2.1$ blocker alone and did not further change PPR ( $n=6$; Figures 5B-D). Taken together, these findings show that $\mathrm{ACh}$ is not additive to $\mathrm{Ca}_{\mathrm{V}} 2.1$ channel block, suggesting that ACh's suppression of the OCX $\rightarrow$ GC EPSC is independent and upstream of $\mathrm{Ca}_{\mathrm{V}} 2.1$ channels, although we cannot exclude ACh also having some post-synaptic action.

\section{DISCUSSION}

STP is a feature of many synaptic connections in the brain and is thought to be involved in sensory processing and memory formation. The present findings indicate there is strong frequency-dependent, STP at glutamatergic synapses from OCX to OB GCs. We further show that this plasticity requires $\mathrm{Ca}_{\mathrm{V}} 2.1$ channels and is not modulated by centrifugal cholinergic afferents. The $\mathrm{OB} \rightarrow \mathrm{OCX} \rightarrow \mathrm{OB}$ feedback loop is a rapid tri-synaptic circuit. The function of this feedback loop is poorly understood but is thought to be fundamental to odor processing and the oscillatory dynamics of $\mathrm{OB}$ during exploratory sniffing (Kiselycznyk et al., 2006; Labarrera et al., 2013; Nunez-Parra et al., 2013). The present findings show that cortical feedback part of the circuit exhibits strong short-term facilitation at frequencies corresponding to investigatory sniffing. This could increase excitation of GCs and thereby decrease the excitability of $\mathrm{OB}$ output neurons during bouts of sniffing odorants.

\section{Short Term Synaptic Plasticity}

Electrical stimulation of centrifugal axons projecting into the bulb induces long-term (Gao and Strowbridge, 2009; Cauthron and Stripling, 2014) and STP (Balu et al., 2007) of GC synaptic responses. The origin of the stimulated fibers in these studies is unclear as electrical stimulation activates all input fibers, which comprise a mix of glutamatergic, cholinergic, GABAergic, noradrenergic and serotonergic inputs (Fallon and Moore, 1978; Macrides et al., 1981; McLean et al., 1989; Ennis et al., 2015). The present study used gene-targeted viruses to drive ChR2 expression selectively in glutamatergic OCX $\rightarrow$ OB axons. We show that there is robust, STP at the OCX $\rightarrow$ GC synapse. PPD at high frequency $(20 \mathrm{~Hz}, 50 \mathrm{~ms}$ inter-stimulus interval) is consistent with models of vesicular availability limiting transmitter release from a second stimulus at a short interval (Wesseling and Lo, 2002; Zucker and Regehr, 2002). The number of synaptic vesicles released depends on the size of readilyreleasable pool and the initial probability of release (Fioravante and Regehr, 2011). During high frequency stimulation, the readily releasable vesicle pool is depleted more quickly than it can be replenished. As the number of vesicles in the readily releasable pool becomes rate limiting, subsequent stimuli release fewer vesicles resulting short-term PPD (Zucker and Regehr, 2002).

At resting respiration rates of $\leq 2 \mathrm{~Hz}$ there was neither PPD or $\mathrm{PPF}$, suggesting a "neutral" plasticity setpoint corresponding to quiet breathing. In contrast, at frequencies spanning investigative sniffing rates (4-10 Hz; Wachowiak, 2011) there was robust $\mathrm{PPF}$ at the OCX $\rightarrow \mathrm{GC}$ synapse. Thus, whether this synapse shows depression or facilitation is dependent on input frequency. Balu et al. (2007) reported facilitation across all inter-stimulus intervals from $5 \mathrm{~Hz}$ to $50 \mathrm{~Hz}$ using electrical stimulation, which would activate a mix of transmitter-specific centrifugal fibers from different brain regions. The present experiments used selective optical activation of ChR2 in vGLUT2cre expressing OCX axons/terminals in the OB. The difference in facilitation frequencies in the two studies raises the interesting possibility that there is heterogeneity in STP from different brain regions. Conceivably, axons from posterior piriform cortex or entorhinal cortex may exhibit different frequency properties to STP from the more anterior OCX region in this study. Synchronous activation of all projections could cause net facilitation masking the frequency dependent depression from 
OCX, whereas selective activation glutamatergic inputs only from OCX in this study exhibits frequency-dependent depression or facilitation.

Mechanisms of STP usually involve presynaptic, voltagegated calcium channels (VGCCs), including N-type, P/Q type and R-type (Reid et al., 2003; Catterall and Few, 2008; Catterall et al., 2013). The types of VGCCs that control transmitter releases vary with different neuron types, brain regions and species. $\mathrm{Ca}_{V} 2.1$ channels have been implicated as a major source of $\mathrm{Ca}^{2+}$ entry and a key determinant of synaptic release. Because of the steep dependence of transmitter release on calcium, even small activity-dependent decreases or increases in calcium entry by modulation of $\mathrm{Ca}_{V} 2.1$ channels can lead to significant short-term depression or facilitation (Forsythe et al., 1998; Xu and Wu, 2005; Catterall et al., 2013). Presynaptic $\mathrm{Ca}_{V} 2.1$ channels cause frequencydependent, bidirectional synaptic plasticity in superior cervical ganglion neurons: PPD at short stimulation intervals $(<50 \mathrm{~ms})$ and facilitation at longer intervals (60-150 ms; Mochida et al., 2008). The present results showed a highly similar frequency-dependent plasticity with depression at short intervals and facilitation at longer intervals. Moreover, selective pharmacologic blockade of the $\mathrm{Ca}_{\mathrm{V}} 2.1$ channels abolished all synaptic plasticity at the glutamatergic OCX $\rightarrow$ GC synapse, indicating strong dependence on the $\mathrm{Ca}_{\mathrm{V}} 2.1$ channels at this synapse. However, other Cav channels may also be involved in STP and remain to be explored at the OCX to GC synapse.

\section{ACh Modulation of Cortical Glutamatergic Input}

Ach modulation of bulb circuitry is complex with direct and indirect actions upon many of the neuron types in the OB. Activation of muscarinic receptors has been reported to inhibit GC firing, but increase activity-independent transmitter release of GABA from GCs to mitral cells (Castillo et al., 1999). On the other hand, muscarinic receptor activation increases GC excitation by blocking afterhyperpolarization (Pressler et al., 2007). Activation of nicotinic receptors excites both output neurons and multiple classes interneurons (Castillo et al., 1999), including the recently identified deep short axon cells (Burton et al., 2017). Little is known about cholinergic presynaptic modulation of centrifugal axons/terminals in OB. In other brain regions, ACh directly modulates $\mathrm{Ca}_{\mathrm{V}} 2.1$ calcium channels in presynaptic terminals (Perez-Rosello et al., 2005; Lawrence et al., 2015). In the present study ACh in a dose-dependently attenuated OCX terminal-evoked EPSCs in GCs, but did not modulate PPD or PPF. Thus, ACh's actions appear to be independent of the $\mathrm{Ca}_{\mathrm{V}} 2.1$ channel, although its reduction of

\section{REFERENCES}

Abbott, L. F., and Regehr, W. G. (2004). Synaptic computation. Nature 431, 796-803. doi: 10.1038/nature03010

Balu, R., Pressler, R. T., and Strowbridge, B. W. (2007). Multiple modes of synaptic excitation of olfactory bulb granule cells. J. Neurosci. 27, 5621-5632. doi: 10.1523/JNEUROSCI.4630-06.2007
EPSC peak amplitude at this synapse suggests it modulates other voltage-gated channels or other components of synaptic machinery. One potential mechanism would be reduction in vesicle content or availability, which would reduce amplitude but not alter the release machinery underlying STP.

Neuropharmacologic-behavior studies suggest that ACh modulates olfactory memory. Blockade of muscarinic receptors impairs short-term olfactory memory (Ravel et al., 2003), while blockade of nicotinic transmission depresses discrimination between similar odorants (Mandairon et al., 2006). Although these studies suggest that cholinergic receptors are involved in STP, they do not identify the neuron type(s) or circuits that mediate complex behavioral processes at the circuit level. Our findings suggest that one of many possible targets is the $\mathrm{OCX} \rightarrow \mathrm{GC}$ synapse.

\section{Function Implications}

GCs are activated by dendrodendritic excitation M/TCs, which also send excitatory synapses to OCX neurons. Many OCX neurons project back to the $\mathrm{OB}$ and form glutamatergic, excitatory synapses onto GCs. GCs also make reciprocal dendrodendritic synapses with M/TCs and can inhibit M/TCs. Thus, GCs are situated to respond dynamically to multiple sources of synaptic input to shape $\mathrm{OB}$ output to other brain regions. Modulation of the $\mathrm{OCX} \rightarrow \mathrm{GC}$ synapse could strongly regulate their inhibitory action on M/TCs. Frequency-dependent STP of the OCX $\rightarrow$ GC synapse as shown may determine the precise balance of excitation and inhibition of GCs. Animals adjust their sniffing according to the salience of odorant stimuli. At quiescent respiration rates $(\leq 2 \mathrm{~Hz})$ there is neither facilitation or depression, but as sniff rate increases the OCX $\rightarrow$ GC synapse would be progressively facilitated increasing inhibition of $\mathrm{OB}$ output neurons. Frequency-dependent enhancement of the OCX $\rightarrow$ GC synapse might preferentially reduce output neuron firing during investigative sniffing when animals attend to salient stimuli, however it is unclear how prolonged sniffing at high frequency may affect potentiation/depression as synapses may deplete during train stimulation. This could enhance OB signalto-noise ratios to facilitate odor processing.

\section{AUTHOR CONTRIBUTIONS}

MS, AP and F-WZ designed the experiments and wrote the article. F-WZ performed and analyzed the experiments.

\section{FUNDING}

This work was supported by National Institutes of Health grants R01DC010915 and R01DC005676.

Boyd, A. M., Sturgill, J. F., Poo, C., and Isaacson, J. S. (2012). Cortical feedback control of olfactory bulb circuits. Neuron 76, 1161-1174. doi: 10.1016/j.neuron. 2012.10.020

Burton, S. D., LaRocca, G., Liu, A., Cheetham, C. E., and Urban, N. N. (2017) Olfactory bulb deep short-axon cells mediate widespread inhibition of tufted cell apical dendrites. J. Neurosci. 37, 1117-1138. doi: 10.1523/JNEUROSCI. 2880-16.2016 
Carson, K. A. (1984). Quantitative localization of neurons projecting to the mouse main olfactory bulb. Brain Res. Bull. 12, 629-634. doi: 10.1016/03619230(84)90143-6

Castillo, P. E., Carleton, A., Vincent, J. D., and Lledo, P. M. (1999). Multiple and opposing roles of cholinergic transmission in the main olfactory bulb. J. Neurosci. 19, 9180-9191. doi: 10.1523/JNEUROSCI.19-21-09180.1999

Catterall, W. A., and Few, A. P. (2008). Calcium channel regulation and presynaptic plasticity. Neuron 59, 882-901. doi: 10.1016/j.neuron.2008.09.005

Catterall, W. A., Leal, K., and Nanou, E. (2013). Calcium channels and short-term synaptic plasticity. J. Biol. Chem. 288, 10742-10749. doi: 10.1074/jbc.r112. 411645

Cauthron, J. L., and Stripling, J. S. (2014). Long-term plasticity in the regulation of olfactory bulb activity by centrifugal fibers from piriform cortex. J. Neurosci. 34, 9677-9687. doi: 10.1523/JNEUROSCI.1314-14.2014

Chamberland, S., Evstratova, A., and Tóth, K. (2017). Short-term facilitation at a detonator synapse requires the distinct contribution of multiple types of voltage-gated calcium channels. J. Neurosci. 37, 4913-4927. doi: 10.1523/JNEUROSCI.0159-17.2017

Davis, B. J., and Macrides, F. (1981). The organization of centrifugal projections from the anterior olfactory nucleus, ventral hippocampal rudiment and piriform cortex to the main olfactory bulb in the hamster: an autoradiographic study. J. Comp. Neurol. 203, 475-493. doi: 10.1002/cne.902030310

Diodato, A., Ruinart de Brimont, M., Yim, Y. S., Derian, N., Perrin, S., Pouch, J., et al. (2016). Molecular signatures of neural connectivity in the olfactory cortex. Nat. Commun. 7:12238. doi: 10.1038/ncomms12238

Ennis, M., Puche, A. C., Holy, T., and Shipley, M. T. (2015). "The olfactory system," in The Rat Nervous System: Fourth Edition, ed. G. Paxinos (London: Elsevier Inc.), 761-803.

Fallon, J. H., and Moore, R. Y. (1978). Catecholamine innervation of the basal forebrain. III. Olfactory bulb, anterior olfactory nuclei, olfactory tubercle and piriform cortex. J. Comp. Neurol. 180, 533-544. doi: 10.1002/cne.901800309

Fioravante, D., and Regehr, W. G. (2011). Short-term presynaptic plasticity. Curr. Opin. Neurobiol. 21, 269-274. doi: 10.1016/j.conb.2011.02.003

Forsythe, I. D., Tsujimoto, T., Barnes-Davies, M., Cuttle, M. F., and Takahashi, T. (1998). Inactivation of presynaptic calcium current contributes to synaptic depression at a fast central synapse. Neuron 20, 797-807. doi: 10.1016/s08966273(00)81017-x

Franklin, K. B. J. and Paxinos, G. (2008). The Mouse Brain in Stereotaxic Coordinate. 3rd Edn., New York, NY: Academic Press.

Gao, Y., and Strowbridge, B. W. (2009). Long-term plasticity of excitatory inputs to granule cells in the rat olfactory bulb. Nat. Neurosci. 12, 731-733. doi: $10.1038 / \mathrm{nn} .2319$

Ichikawa, T., and Hirata, Y. (1986). Organization of choline acetyltransferasecontaining structures in the forebrain of the rat. J. Neurosci. 6, 281-292. doi: 10.1523/JNEUROSCI.06-01-00281.1986

Isaacson, J. S., and Strowbridge, B. W. (1998). Olfactory reciprocal synapses: dendritic signaling in the CNS. Neuron 20, 749-761. doi: 10.1016/s08966273(00)81013-2

Kasa, P., Hlavati, I., Dobo, E., Wolff, A., Joo, F., and Wolff, J. R. (1995). Synaptic and non-synaptic cholinergic innervation of the various types of neurons in the main olfactory bulb of adult rat: immunocytochemistry of choline acetyltransferase. Neuroscience 67, 667-677. doi: 10.1016/0306-4522(95) 00031-d

Kiselycznyk, C. L., Zhang, S., and Linster, C. (2006). Role of centrifugal projections to the olfactory bulb in olfactory processing. Learn. Mem. 13, 575-579. doi: $10.1101 / \mathrm{lm} .285706$

Labarrera, C., London, M., and Angelo, K. (2013). Tonic inhibition sets the state of excitability in olfactory bulb granule cells. J. Physiol. 591, 1841-1850. doi: 10.1113/jphysiol.2012.241851

Lawrence, J. J., Haario, H., and Stone, E. F. (2015). Presynaptic cholinergic neuromodulation alters the temporal dynamics of short-term depression at parvalbumin-positive basket cell synapses from juvenile CA1 mouse hippocampus. J. Neurophysiol. 113, 2408-2419. doi: 10.1152/jn.00167.2014

Li, L., Mi, Y., Zhang, W., Wang, D. H., and Wu, S. (2018). Dynamic information encoding with dynamic synapses in neural adaptation. Front. Comput. Neurosci. 12:16. doi: 10.3389/fncom.2018.00016

Liberia, T., Blasco-Ibáñez, J. M., Nácher, J., Varea, E., Lanciego, J. L., and Crespo, C. (2015). Synaptic connectivity of the cholinergic axons in the olfactory bulb of the cynomolgus monkey. Front. Neuroanat. 9:28 doi: 10.3389/fnana.2015.00028

Liu, S., Plachez, C., Shao, Z., Puche, A., and Shipley, M. T. (2013). Olfactory bulb short axon cell release of GABA and dopamine produces a temporally biphasic inhibition-excitation response in external tufted cells. J. Neurosci. 33, 2916-2926. doi: 10.1523/JNEUROSCI.3607-12.2013

Liu, S., Puche, A. C., and Shipley, M. T. (2016). The interglomerular circuit potently inhibits olfactory bulb output neurons by both direct and indirect pathways. J. Neurosci. 36, 9604-9617. doi: 10.1523/JNEUROSCI.176316.2016

Luskin, M. B., and Price, J. L. (1983). The topographic organization of associational fibers of the olfactory system in the rat, including centrifugal fibers to the olfactory bulb. J. Comp. Neurol. 216, 264-291. doi: 10.1002/cne.9021 60305

Luvisetto, S., Fellin, T., Spagnolo, M., Hivert, B., Brust, P. F., Harpold, M. M., et al. (2004). Modal gating of human Cav2.1 (P/Q-type) calcium channels: I. The slow and the fast gating modes and their modulation by $\beta$ subunits. J. Gen. Physiol. 124, 445-461. doi: 10.1085/jgp.200409034

Macrides, F., Davis, B. J., Youngs, W. M., Nadis, N. S., and Margolis, F. L. (1981). Cholinergic and catecholaminergic afferents to the olfactory bulb in the hamster: a neuroanatomical, biochemical and histochemical investigation. J. Comp. Neurol. 203, 497-516. doi: 10.1002/cne.902030311

Mandairon, N., Ferretti, C. J., Stack, C. M., Rubin, D. B., Cleland, T. A., and Linster, C. (2006). Cholinergic modulation in the olfactory bulb influences spontaneous olfactory discrimination in adult rats. Eur. J. Neurosci. 24, 3234-3244. doi: 10.1111/j.1460-9568.2006.05212.x

Markopoulos, F., Rokni, D., Gire, D. H., and Murthy, V. N. (2012). Functional properties of cortical feedback projections to the olfactory bulb. Neuron 76, 1175-1188. doi: 10.1016/j.neuron.2012.10.028

Mazo, C., Lepousez, G., Nissant, A., Valley, M. T., and Lledo, P. M. (2016). $\mathrm{GABA}_{\mathrm{B}}$ receptors tune cortical feedback to the olfactory bulb. J. Neurosci. 36, 8289-8304. doi: 10.1523/JNEUROSCI.3823-15.2016

McLean, J. H., Shipley, M. T., Nickell, W. T., Aston-Jones, G., and Reyher, C. K. (1989). Chemoanatomical organization of the noradrenergic input from locus coeruleus to the olfactory bulb of the adult rat. J. Comp. Neurol. 285, 339-349. doi: 10.1002/cne.902850305

Mintz, I. M., Venema, V. J., Swiderek, K. M., Lee, T. D., Bean, B. P., and Adams, M. E. (1992). P-type calcium channels blocked by the spider toxin $\omega$-Aga-IVA. Nature 355, 827-829. doi: 10.1038/355827a0

Mochida, S., Few, A. P., Scheuer, T., and Catterall, W. A. (2008). Regulation of presynaptic Cav2.1 channels by $\mathrm{Ca}^{2+}$ sensor proteins mediates short-term synaptic plasticity. Neuron 57, 210-216. doi: 10.1016/j.neuron.2007. 11.036

Mori, K., Matsumoto, H., Tsuno, Y., and Igarashi, K. M. (2009). Dendrodendritic synapses and functional compartmentalization in the olfactory bulb. Ann. NY Acad. Sci. 1170, 255-258. doi: 10.1111/j.1749-6632.2009.03881.x

Nickell, W. T., and Shipley, M. T. (1988). Neurophysiology of magnocellular forebrain inputs to the olfactory bulb in the rat: frequency potentiation of field potentials and inhibition of output neurons. J. Neurosci. 8, 4492-4502. doi: 10.1523/JNEUROSCI.08-12-04492.1988

Nimmrich, V., and Gross, G. (2012). P/Q-type calcium channel modulators. Br. J. Pharmacol. 167, 741-759. doi: 10.1111/j.1476-5381.2012.02069.x

Nunez-Parra, A., Maurer, R. K., Krahe, K., Smith, R. S., and Araneda, R. C. (2013). Disruption of centrifugal inhibition to olfactory bulb granule cells impairs olfactory discrimination. Proc. Natl. Acad. Sci. U S A 110, 14777-14782. doi: $10.1073 /$ pnas. 1310686110

Otazu, G. H., Chae, H., Davis, M. B., and Albeanu, D. F. (2015). Cortical feedback decorrelates olfactory bulb output in awake mice. Neuron 86, 1461-1477. doi: 10.1016/j.neuron.2015.05.023

Perez-Rosello, T., Figueroa, A., Salgado, H., Vilchis, C., Tecuapetla, F., Guzman, J. N., et al. (2005). Cholinergic control of firing pattern and neurotransmission in rat neostriatal projection neurons: role of $\mathrm{Ca}_{V} 2.1$ and Cav2.2 $\mathrm{Ca}^{2+}$ channels. J. Neurophysiol. 93, 2507-2519. doi: 10.1152/jn.00853. 2004

Pressler, R. T., Inoue, T., and Strowbridge, B. W. (2007). Muscarinic receptor activation modulates granule cell excitability and potentiates inhibition onto mitral cells in the rat olfactory bulb. J. Neurosci. 27, 10969-10981. doi: 10.1523/JNEUROSCI.2961-07.2007 
Ravel, N., Elaagouby, A., and Gervais, R. (2003). Scopolamine injection into the olfactory bulb impairs short-term olfactory memory in rats. Behav. Neurosci. 108, 317-324. doi: 10.1037/0735-7044.108.2.317

Reid, C. A., Bekkers, J. M., and Clements, J. D. (2003). Presynaptic Ca ${ }^{2+}$ channels: a functional patchwork. Trends Neurosci. 26, 683-687. doi: 10.1016/j.tins.2003. 10.003

Rothermel, M., Carey, R. M., Puche, A., Shipley, M. T., and Wachowiak, M. (2014). Cholinergic inputs from Basal forebrain add an excitatory bias to odor coding in the olfactory bulb. J. Neurosci. 34, 4654-4664. doi: 10.1523/JNEUROSCI. 5026-13.2014

Shipley, M. T., and Adamek, G. D. (1984). The connections of the mouse olfactory bulb: a study using orthograde and retrograde transport of wheat germ agglutinin conjugated to horseradish peroxidase. Brain Res. Bull. 12, 669-688. doi: 10.1016/0361-9230(84)90148-5

Shipley, M. T., and Ennis, M. (1996). Functional organization of olfactory system. J. Neurobiol. 30, 123-176. doi: 10.1002/(sici)1097-4695(199605)30:1<123::aidneu11>3.0.co; $2-\mathrm{n}$

Wachowiak, M. (2011). All in a sniff: olfaction as a model for active sensing. Neuron 71, 962-973. doi: 10.1016/j.neuron.2011.08.030

Wang, X., McKenzie, J. S., and Kemm, R. E. (1996). Whole cell calcium currents in acutely isolated olfactory bulb output neurons of the rat. J. Neurophysiol. 75, 1138-1151. doi: 10.1152/jn.1996.75.3.1138

Wesseling, F., and Lo, D. C. (2002). Limit on the role of activity in controlling the release-ready supply of synaptic vesicles. J. Neurosci. 22, 9708-9720. doi: 10.1523/JNEUROSCI.22-22-09708.2002

Westenbroek, R. E., Sakurai, T., Elliott, E. M., Hell, J. W., Starr, T. V., Snutch, T. P., et al. (1995). Immunochemical identification and subcellular distribution of the alpha 1A subunits of brain calcium channels. J. Neurosci. 15, 6403-6418. doi: 10.1523/JNEUROSCI.15-10-06403.1995
Wilson, D. A., Best, A. R., and Sullivan, R. M. (2004). Plasticity in the olfactory system: lessons for the neurobiology of memory. Neuroscientist 10, 513-524. doi: $10.1177 / 1073858404267048$

$\mathrm{Xu}, \mathrm{J}$., and $\mathrm{Wu}, \mathrm{L}$. G. (2005). The decrease in the presynaptic calcium current is a major cause of short-term depression at a calyx-type synapse. Neuron 46, 633-645. doi: 10.1016/j.neuron.2005.03.024

Zhou, F. W., Dong, H. W., and Ennis, M. (2016). Activation of $\beta$ noradrenergic receptors enhances rhythmic bursting in mouse olfactory bulb external tufted cells. J. Neurophysiol. 116, 2604-2614. doi: 10.1152/jn. 00034.2016

Zhou, F. W., Jin, Y., Matta, S. G., Xu, M., and Zhou, F. M. (2009). An ultra-short dopamine pathway regulates basal ganglia output. J. Neurosci. 29, 10424-10435. doi: 10.1523/JNEUROSCI.4402-08.2009

Zhou, F. W., and Roper, S. N. (2011). Altered firing rates and patterns in interneurons in experimental cortical dysplasia. Cereb. Cortex 21, 1645-1658. doi: 10.1093/cercor/bhq234

Zucker, R. S., and Regehr, W. G. (2002). Short-term synaptic plasticity. Annu. Rev. Physiol. 64, 355-405. doi: 10.1146/annurev.physiol.64.092501.114547

Conflict of Interest Statement: The authors declare that the research was conducted in the absence of any commercial or financial relationships that could be construed as a potential conflict of interest.

Copyright (c) 2018 Zhou, Puche and Shipley. This is an open-access article distributed under the terms of the Creative Commons Attribution License (CC BY). The use, distribution or reproduction in other forums is permitted, provided the original author(s) and the copyright owner(s) are credited and that the original publication in this journal is cited, in accordance with accepted academic practice. No use, distribution or reproduction is permitted which does not comply with these terms. 